\title{
Clinical Trial Information
}

National Cancer Institute

\section{Source}

National Cancer Institute. Clinical Trial Information. NCI Thesaurus. Code C142447.

Any and all information related to a clinical study, including study or trial data, data integrity information, and administration. 